\title{
LUT
}

Lappeenranta

University of Technology

\section{Production and characterization of coffee-pine wood residue briquettes as an alternative fuel for local firing systems in Brazil}

\begin{abstract}
Mendoza Martinez Clara Lisseth, Sermyagina Ekaterina, de Cassia Oliveira Carneiro Angélica, Vakkilainen Esa, Cardoso Marcelo
\end{abstract}

This is a Post-print version of a publication

published by Elsevier

in Biomass and Bioenergy

DOI: $10.1016 /$ j.biombioe.2019.02.013

Copyright of the original publication: () 2019 Elsevier Ltd.

Please cite the publication as follows:

Mendoza Martinez Clara Lisseth, Sermyagina Ekaterina, de Cassia Oliveira Carneiro Angélica, Vakkilainen Esa, Cardoso Marcelo. (2019). Production and characterization of coffee-pine wood residue briquettes as an alternative fuel for local firing systems in Brazil. Biomass and Bioenergy, Vol 123. p. 70-77. DOI: 10.1016/j.biombioe.2019.02.013 
1

\section{PRODUCTION AND CHARACTERIZATION OF COFFEE-PINE WOOD RESIDUE BRIQUETTES AS AN ALTERNATIVE FUEL FOR LOCAL FIRING SYSTEMS IN BRAZIL}

Clara Lisseth Mendoza Martinez ${ }^{a b c *}$, Ekaterina Sermyagina ${ }^{b}$, Angélica de Cassia Oliveira

Carneiro $^{c}$, Esa Vakkilainen ${ }^{b}$, Marcelo Cardoso $^{a}$

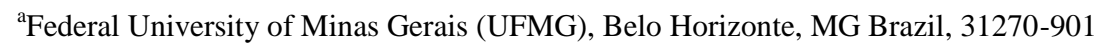

${ }^{b}$ Lappeenranta University of Technology, Skinnarilankatu 34, FI-53850 Lappeenranta, Finland

${ }^{c}$ Federal University of Viçosa (UFV), Viçosa, MG, Brazil, 36.570-000

ABSTRACT - In this work, the production viability, physical, chemical and mechanical properties of briquettes produced from mixtures of coffee shrub residues and pinewood, were evaluated. The densification was carried out under constant operating conditions (temperature of $120{ }^{\circ} \mathrm{C}$, pressure of $8.27 \mathrm{MPa}$ ) in a piston-press type laboratory-scale briquetting machine. Coffee shrub residues were mixed with pinewood in ratios of $25 \%, 50 \%$ and $75 \%$. In addition, reference briquettes of pure pinewood and of each type of coffee shrub residue were produced. To characterize the raw material, ash content, volatile matter, fixed carbon together with the calorific value of produced samples, were measured. To characterize the suitability of the briquettes produced: apparent density, energy density, tensile strength, and equilibrium moisture content were determined. The highest values of energy density $\left(19133-19899 \mathrm{MJ} \cdot \mathrm{m}^{-3}\right)$, tensile strength (415 - $569 \mathrm{kgf})$, apparent density $\left(1107-1163 \mathrm{~kg} \cdot \mathrm{m}^{-3}\right)$ and favorable values of equilibrium moisture content $(9-11$ wt \%) were obtained from a mixing ratio of $75 \%$ of pinewood. The novel contribution of this research was to develop briquettes with appropriate physical and mechanical parameters from new raw materials that could serve as sustainable fuel sources for local firing systems.

Keywords: Densification; coffee residues; pinewood; briquette; physical properties

*Corresponding Author at: School of Chemical Engineering, Federal University of Minas Gerais, room 5210, block 2, 6627 Antonio Carlos Road, 31270901, Belo Horizonte, Minas Gerais, Brazil.

E-mail address: clara.mendoza.martinez@gmail.com 


\section{INTRODUCTION}

28 In brazil, utilization of biomass from agriculture, agroindustry and forestry are advantageous 29 as their availability is not hindered by a requirement for arable land for food and feed production 30 [1]. It is estimated that more than 200 million tons from agroindustry residues are not utilized 31 energetically, mainly due to their poor energy characteristics: e.g. low density, low heating value 32 and high moisture content [2]. In order for biomass to be considered for implementation as a 33 viable fuel, it must be transformed into a readily useable and high energy resource.

34 Technologies that can transform firewood, agroforestry and industrial residues into a final 35 product with high potential properties are attractive for the Brazilian energy matrix. One 36 alternative to conventional energy sources is the utilization of pressed residues in the form of 37 briquettes or pellets. Thus, the proper densification contributes to high volumetric concentration 38 of energy, improving the handling and reducing the volume and resulting storage and transport 39 costs [3]

\section{$40 \quad 1.1$ Biomass briquetting in brazil}

41 Briquettes have long been used by residences, industries and commercial establishments, 42 substituting for considerable quantities of firewood that would otherwise be extracted from the 43 forest, thereby reducing negative environmental impacts. Briquettes in Brazil are used as 44 substitutes for firewood in bakeries, food establishments, pizza restaurants, as well as factories 45 with fuelwood-burning furnaces, like red brick factories [4], [5]. Briquetting activities in Brazil 46 are limited to those few regions with high wood residues concentrations, such as the states of Sao 47 Paulo, Santa Catarina and Mato Grosso [5]. Nevertheless, the quest for sustainability and the so48 called green economy has contributed to expanding consumption, and consequently, the 49 production of briquettes. This expansion primarily depends on three factors: residue availability, 50 adequate technologies and a growing market for briquettes[5].

51 Briquetting presents an efficient densification process that produces a uniform fuel, increases 52 the energy density and reduces the transport and handling costs of the biomass residues [6], [7]. 53 The briquettes are generally produced in a piston (mechanical or hydraulic) press by applying 54 load on a die with biomass particles. Additional binder and heat treatments can be applied 
55 depending on the properties of the feedstock [5]. To evaluate the final product, resistance to 56 compression, energy density, compaction rate and equilibrium moisture, among others 57 properties, should be measured [8].

58 Several studies have evaluated the possibility of utilizing different agricultural wastes and by59 products for briquetting. A number of authors have investigated rice residue potential: analyzing 60 the briquettes from rice straw and rice bran [10]-[12]; briquetting of rice and coffee husks for 61 domestic cooking applications [13]; production of activated carbon briquettes from rice husks 62 and eucalyptus wood [14]. Very positive results were obtained from blends of rice husks with 63 corn cobs [15], [16] and other residues of corn [17], [18]. This rational use of biomass tends to 64 promote the development of less economically favored regions, through the creation of jobs and 65 reduction of external energy dependence, based on their local availability. The advantage of 66 briquettes being manufactured from industrial and agroforestry residues is that their resulting 67 price is lower compared to a large variety of fuels: e.g. charcoal [3], [9].

\subsection{Coffee residual biomass potential}

The coffee production chain generates a large quantity of residues from both the berries (beans) themselves and the shrub. It is estimated that over ten million tons of residues yearly (solid and liquid) are produced [19]. In addition, there are residues from cultivation (pruning), which are difficult to estimate due to the differences in agronomic management practices. Brazil is the largest producer and exporter of coffee in the world. About 2.78 million tons of coffee beans were produced in 2016-2017. From this production, approximately 2.3 million tons of solid residues are generated each year [20]. Currently, these residues; coffee pulp, parchment, coffee wood and effluents, are not utilized efficiently and can result in severe environmental impacts due to inappropriate disposal [21]. The disposal of coffee wastes remains a challenge due to the presence of caffeine, free phenols and tannins (polyphenols), which are even toxic to many forms of life [22]. Currently, only a small fraction of available coffee pulp and parchment is utilized; as fertilizers, livestock feed, etc. The possibility of improving the properties and converting the waste streams into a competitive fuel in the energy market (production of solid fuels [briquettes, pellets and charcoal], biogas, liquid fuels) or extraction of the valuable chemicals from them may result in not only environmental but economic benefits as well. For 
84 this reason, it is necessary to develop the pretreatment technologies to improve the biomass

85 feedstock characteristics and make it more suitable for energy or chemical applications.

86 As for coffee by-products themselves, there is still very little information about the energy 87 potential and specific characteristics of the treatments for the residues from the coffee production 88 chain. Only a few works present some results on the possible utilization pathways for these 89 materials. One study [23] analyzed a process of anaerobic co-digestion of coffee husks and 90 microalgal biomass after thermal hydrolysis pretreatment. In another work, high temperature air91 steam gasification of coffee husks was studied experimentally [24]. Another group of researchers 92 provided the results of their two-dimensional CFD simulation of the coffee husks' gasification in 93 a fluidized bed reactor [25]. In addition to the residues typically associated with coffee 94 production, the coffee chain provides another potentially abundant energy source, coffee wood 95 [26]. Ethanol fermentation and gasification of coffee wood were evaluated by [27]. Additionally, 96 it was proven that gasification represents a promising way to convert coffee wood into energy 97 with high energy yields and resultingly low environmental impacts.

98 According to [26], the energy potential of coffee residues - coffee husk and coffee wood - in 99 Brazil is highly significant with annual available energy of $11.3 \mathrm{PJ}$ and $49.5 \mathrm{PJ}$, correspondingly. 100 More information is needed to choose the most optimum treatment technology for these residues. 101 Use of coffee residues along with traditional biomasses already utilized in the production of 102 briquettes, such as pinewood, may considerably improve the potential of coffee residue 103 utilization. Pine cultivation areas occupy a rather significant landmass in Brazil with $1.58 \cdot 10^{6}$ ha 104 planted in 2015, so the availability of feedstock would not be a limiting factor [28]. Additionally, 105 pinewood is rich in natural resins that increase its calorific value [29]. It also has a high lignin 106 and silica content in its composition. Briquettes production would not require any additional 107 binders since lignin acts as a natural binding material during the pressing process. The present 108 work analyses the viability of a briquetting process for the mixture of residues from the coffee 109 production chain and pinewood to produce a solid fuel of regular shape and high energy density 110 and resistance, for use in local firing systems.

\section{MATERIALS AND METHODS}


Three biomass materials were studied: coffee wood, the coffee berry parchment layer (this covers the coffee beans and represents about $12 \mathrm{wt} \%$ of the berry on a dry basis) and pinewood. The coffee (Coffea Arabica L.) residues were provided by a rural farm in the municipality of Paula Cândido, Minas Gerais state, Brazil (2049'50.0" S 4255'03.3" W). The plant cultivation was established in 1986, and due to low productivity, stumping of new plant formation was required. The wood collected was 11 years old (from subsequent to the last stumping period). The coffee wood samples were separated into (I) stems, (II) primary branches and (III) secondary branches according to their diameter, $10 \pm 2 \mathrm{~cm}, 2 \pm 1 \mathrm{~cm}$ and $1 \pm 0.5 \mathrm{~cm}$, respectively. The three components were considered separately mainly due to coffee shrub aerial morphology, which is related to two types of burgeon: ortho-tropics (coffee beans grown on the stem) and plagiotropic (coffee beans grown on the branches). In addition, previous analysis had reveales chemical differences between coffee stem, primary and secondary branches [30]. The pinewood residues were collected at the commercial cultivation sites of the experimental units of the Federal University of Viçosa, Minas Gerais State, Brazil (2045'14" S 4252'55"). The wood collected was 7 years old (from subsequent to the last stumping period).

The research from the experiments presented in this work was composed of two stages:

i) Classification, physical and chemical characterization of biomasses;

ii) Production of briquettes and their physical, mechanical and chemical characterization.

\subsection{Classification and characterization of biomass feedstock}

133 All biomasses were initially ground in a Weg® electric hammer mill at a fixed speed of 368.6 $134 \mathrm{rad} \cdot \mathrm{sec}^{-1}$, which was coupled with a $2 \mathrm{~mm}$ opening sieve. For the samples intended for proximate 135 analysis, the particle size was further reduced using a Thomas model 4 Wiley® knife mill with a 136 fixed speed of $83.7 \mathrm{rad} \cdot \mathrm{sec}^{-1}$ at $60 \mathrm{~Hz}$. The biomasses were finally classified into superposed 137 sieves with openings of 40 mesh $(0.47 \mathrm{~mm})$ and 60 mesh $(0.31 \mathrm{~mm})$ according to German 138 Institute for Standardization (DIN) EN 14780, 2017 routine procedure [31]. 
The moisture content (MC) was determined according to DIN EN 14774-1, 2010 standard procedure [32], by keeping the sample in an oven at $105 \pm 2{ }^{\circ} \mathrm{C}$ until the constant mass was obtained. The ash content (AC) was determined according to DIN EN 14775, 2012 standard [33], as the residue after complete combustion by the gradual heating of the sample in the muffle oven with the maximum temperature of $550{ }^{\circ} \mathrm{C}$. The volatile matter (VM) was measured as mass loss after devolatilization of the samples in the oven at $900{ }^{\circ} \mathrm{C}$ according to DIN EN 15148, 2010 standard [34]. The fixed carbon (FC) was calculated as the difference between 100 and the sum of all measured components.

The bulk density was measured with the standard procedure presented in DIN EN 15103, 2010 [35]. The higher heating value (HHV) was obtained using an adiabatic calorimetric pump IKA300 according to DIN EN 14918, 2014 procedure[36].

\subsection{Production and characterization of Briquettes}

The recommended moisture range of the feedstock materials before the briquetting process varies from $8 \mathrm{wt} \%$ to $15 \mathrm{wt} \%$ on a wet basis (wb). In this work, the biomass samples were dried in an oven at $25^{\circ} \mathrm{C}$, until reaching $8 \pm 0.5 \mathrm{wt} \%(\mathrm{wb})$ of moisture content. The initial moisture of the samples was $20 \mathrm{wt} \%, 17 \pm 5 \mathrm{wt} \%$ and $12 \mathrm{wt} \%$ (wb) for pinewood, shrub coffee woody parts and parchment, respectively. The briquettes were produced in a piston-press type of the laboratory-scale briquetting machine from Lippel®, model LB 32. The briquetting conditions were defined experimentally from preliminary tests carried out in the laboratory. The materials were compressed for $4 \mathrm{~min}$ at a temperature of $120{ }^{\circ} \mathrm{C}$ and pressure of $8.27 \mathrm{MPa}$ with a subsequent cooling for 8 min. Pinewood was mixed in ratios of $25 \%, 50 \%$ and $75 \%$ with stem, primary branch, secondary branch and a mixture of all woody parts of coffee shrub, and coffee berry parchment. The presence of stems, and primary \& secondary branches were proportional in the mixture of all woody parts. At the end of the homogenization of the biomasses, $20 \mathrm{~g}$ of mixture was weighed and placed in a steel capsule $(10 \mathrm{~cm}$ long and $3 \mathrm{~cm}$ in diameter) in the briquetting machine. 10 briquettes per treatment were manufactured.

After cooling, the briquettes were kept in an air-conditioned chamber at a temperature of $23 \pm$ $1{ }^{\circ} \mathrm{C}$ and a relative humidity of $60 \pm 10 \%$ until equilibrium moisture content was reached. Visual analysis was taken both before and after conditioning in the climatic chamber to verify the visual appearance of the briquettes. 
The equilibrium moisture content (EMC) was determined by mass difference. Equilibrium was considered as having been reached when the sample mass difference between two successive days was less than the balance accuracy. Apparent density was measured in triplicates by the mercury immersion method according to [37]. The relation between the apparent density of the briquette, and the bulk density of the ground biomass calculated compact rate. The net heating value (NHV), was determined using the equation (1), according to DIN EN 14918 [36]:

$$
N H V=[(H H V-54 \cdot H) \cdot(1-E M C)]-(600 \cdot E M C)
$$

176 Where,

$177 \mathrm{HHV}=$ High heating value $\left(\mathrm{MJ} \cdot \mathrm{kg}^{-1}\right) ; \mathrm{H}=$ Hydrogen content $($ wt \%); EMC= Equilibrium 178 moisture content (wt \%)

179 The energy density was obtained by the multiplication of the apparent density and the NHV.

180 The tensile strength by diametrical compression for briquettes was measured in triplicates 181 according to the guidelines of NBR 7222 standard with adaptations presented in [38]. The tests 182 were carried out in a universal test machine, Contenco brand, UMC-300 model. The result of 183 maximum load was obtained by the Pavitest software 2.7.0.7.

\subsection{Experimental design}

The tests were carried out for the briquettes' composition in a completely randomized factorial design (5x5), considering five mixing ratios of residues $(0 \%, 25 \%, 50 \%, 75 \%$ and $100 \%$ ), five mixing biomasses (stem, primary branch, secondary branch, mixture of wood parts and parchment) and ten replicates, yielding a total of 250 sampling units.

The influence of the pine share in the blend with coffee residues was evaluated and subjected to analysis of variance (ANOVA). The combinations with the significant differences were compared with Tukey's test at a 5\% probability level. Statistical analyzes were performed with the help of the Statistica 8.0 program [39]

For the results on equilibrium moisture content (wt\%), maximum load (kgf), apparent density $\left(\mathrm{kg} \cdot \mathrm{m}^{-3}\right)$ and energy density $\left(\mathrm{MJ} \cdot \mathrm{m}^{-3}\right)$ properties, models were defined with the aid of $\mathrm{R}$ program for explaining the data distribution. The comparison between the treatments was done by the identity model test [40], according to the equation (2) 


$$
\text { Property }=\beta_{0} \cdot \text { Pinewood }^{2} \pm \beta_{1} \cdot \text { Pinewood } \pm \beta_{2}
$$

Where,

\section{RESULTS AND DISCUSSION}

\subsection{Characterization of the feedstock}

The biomass particle size distribution is one of the most important initial characteristics of the raw material with respect to any densification process. Table 1 shows the particles size distribution of the biomasses used for the briquettes production in this study.

Table 1. Particle size distribution of the lignocellulosic residues used in the production of briquettes.

The particle size distribution of the coffee wood residues was relatively similar. The samples had a high percentage $(45.1-51.2 \%)$ of particles with diameters of less than $0.31 \mathrm{~mm}$, which passed through both 40 and 60 mesh sieves. Between $16.6 \%$ and $22.2 \%$ of particles were retained in the 60 mesh sieve (corresponding diameter range between $0.31 \mathrm{~mm}$ and $0.47 \mathrm{~mm}$ ). The bigger particles with diameter between $0.47 \mathrm{~mm}$ and $2 \mathrm{~mm}$ had a share from 26.6 to $38.3 \%$. The coffee parchment had the lowest presence of fines among the studied materials (21.9\%) and the highest share of particles with diameters between $0.47 \mathrm{~mm}$ and $2 \mathrm{~mm}$ (42.8\%). Most probably, the rounded shape of the parchment particles caused the higher resistance to the trituration process and resulted in higher share of larger fractions. Such behavior may be responsible for a decrease in the material homogeneity, strength, durability and resistance of resulting briquettes [41][42]. The pine sawdust contained the highest presence of fine particles $(60.3 \%)$. According to [43] and [44], the quality and volumetric density of briquettes is inversely proportional to the particle size because smaller particles in the feedstock correspond to a larger surface area for bonding during densification. The increased compacting pressure result in the biomass particles being closely packed due to a reduction of void ratio and plastic deformation of the sawdust particles, therefore resulting in higher density of the briquettes [45]. However, very 
small particles can lead to jamming of the briquetting machine and affect the production capacity [46].

\subsubsection{Chemical characterization}

As the objective of this study was the production of solid biofuels, it is desirable for the feedstock materials and consequently the final products to have low ash content, high energy as well as fixed carbon content and low volatile matter. The main combustion properties of the studied lignocellulosic residues are presented in Table 2.

Table 2. Chemical characterization of the lignocellulosic residues.

The feedstock moisture plays an important role in the densification process, considering that water acts as both a binder and a lubricant. Material that is too dry makes the bonding between the particles difficult due to the elevated frictional forces in the compression channel. Excess moisture can cause explosions inside the briquette due to the formation of steam. [47] observed that the moisture in the biomass increases during densification through the van der Waals forces by increasing the contact area between the particles. They also concluded that low moisture content $(5-10 \mathrm{wt} \%)$ results in more stable, resistant and denser briquettes compared to higher moisture biomasses (15 wt\%). Several studies recommended that the feedstock for the briquettes' production should contain a moisture content between 8 - 15 wt \% (wb) [48]. [49], [50] and [51] suggested low feed moisture content in the range of $8-12 \mathrm{wt} \%$ (wb) to produce strong briquettes that are free of cracks. Levels above or below this would lead to densified material of lower quality. [52] studied the compaction of platanus tree chips at different initial moistures (5.7 - $23.9 \mathrm{wt} \%)$ and found that for the briquetting production it is better to use lower moisture content material (up to about $12 \mathrm{wt} \%$ ) because at higher moisture levels a sharp decrease in rupture force and density occurs. The moisture content of the studied biomasses was in a relatively narrow range from $8.7 \mathrm{wt} \%$ to $12.23 \mathrm{wt} \%$, characteristic of the particulate material that influenced in the absence of surface cracks and significant axial expansions in the briquettes.

Volatile matter is the portion of the fuel that is released in form of gases when the material is heated. The more volatile a fuel is, the faster it burns, and the more reactive and more easily it is ignited [53]. In many domestic uses, a slow rate of burning is preferred. The typical volatile matter range for general biomass is $65-85 \mathrm{wt} \%$ and $76-86 \mathrm{wt} \%$ for woody biomass [54]. In 
the current work, the woody residues had a higher share of the volatile matter than the parchment. Pine sawdust followed by the primary branches had the highest VM values of 82.5 wt $\%$ and $80.7 \mathrm{wt} \%$, respectively. Many other materials used in the production of briquettes, such as rice husk (65.5 wt \%), sugarcane bagasse (73.8 wt \%) [55], shea meal (66.3 wt \%) [56], paper sludge (48.7 wt \%) and coal (33.1 wt \%) [57], reveal values of volatile matter lower than the values found for the raw material used in this study, and due to this, the coffee residues and pine wood are attractive for burning processes.

The fixed carbon content is inversely proportional to the volatile matter. The FC for parchment was $20.1 \mathrm{wt} \%$ and for wood residues $14.6 \mathrm{wt} \%-19.4 \mathrm{wt} \%$. According to [58], high FC indicates that the materials tend to burn more slowly, requiring longer residence time compared to fuels with a low FC. This suggests that briquettes containing parchment in their composition may demonstrate a slower burning rate when compared to briquettes manufactured with coffee wood residues.

The ash content implies the presence of inorganic components, mostly in the form of oxides [59]. Due to this, the results indicated the highest inorganic composition of the parchment (5.9 wt $\% \mathrm{db}$ ) followed by the secondary coffee wood branches $(4.1 \mathrm{wt} \% \mathrm{db})$. Other studied materials had a relatively low ash content with the minimum value being for pinewood $(0.8 \mathrm{w} \mathrm{t} \%)$. According to [60], the ash content in the feedstock does not influence the densification process itself. However, an ash content greater than $10 \mathrm{wt} \%$ will cause wear on the equipment matrix.

The elevated heating values were relatively high for all biomasses: from $18.9 \mathrm{MJ} \cdot \mathrm{kg}^{-1}$ for parchment to $20.7 \mathrm{MJ} \cdot \mathrm{kg}^{-1}$ for pinewood. In comparison with other feedstocks generally used in the briquettes' manufacturing, such as rice husk (16.4 MJ. kg-1) [61], wheat straw $\left(16.4 \mathrm{MJ} \cdot \mathrm{kg}^{-1}\right)$, timothy grass (16.3 $\left.\mathrm{MJ} \cdot \mathrm{kg}^{-1}\right)$ [62], sugarcane bagasse $\left(17.3 \mathrm{MJ} \cdot \mathrm{kg}^{-1}\right)$ [55] and eucalyptus wood (19.0 $\mathrm{MJ} \cdot \mathrm{kg}^{-1}$ ) [63], the studied samples present rather attractive materials for briquetting. Higher energy content increases the efficiency of the subsequent utilization of the briquettes and reduces the process costs.

\subsubsection{Bulk density}

Bulk density is an essential factor influencing the economic viability of biomass materials utilization, since it affects the transport costs and the energy density of biomass. For this reason, 
the lignocellulosic residues with higher bulk density values are more desirable for the production of briquettes. The average values of the bulk density of the investigated biomasses are presented in Fig. 1.

Figure 1. Bulk density of studied biomasses (raw material).

The $0 \%$ proportion of pine feedstock had notably higher bulk densities than the other mixtures. The $100 \%$ parchment feedstock showed the highest bulk density $\left(341.5 \mathrm{~kg} \cdot \mathrm{m}^{-3}\right)$ due to high basic density of the material and flat-shaped particles. The addition of pinewood sawdust significantly decreases the density levels of all studied materials. The lowest density was obtained in the case of the mixtures with $75 \%$ of pine: $45 \mathrm{~kg} \cdot \mathrm{m}^{-3}$ on average. The bulk density of the studied biomasses (raw material) used in the production of briquettes is analogous to unprocessed wood residues $\left(250 \mathrm{~kg} \cdot \mathrm{m}^{-3}\right)$ [64], ground switchgrass $\left(181.6 \mathrm{~kg} \cdot \mathrm{m}^{-3}\right)$ [41], wheat straw $\left(97.4-121.3 \mathrm{~kg} \cdot \mathrm{m}^{-3}\right)$, corn stover $\left(131.4-157.7 \mathrm{~kg} \cdot \mathrm{m}^{-3}\right)$ and barley straw $(81-112.1$ $\mathrm{kg} \cdot \mathrm{m}^{-3}$ ) [41]. The decrease in bulk density when mixing residual biomasses from the coffee production chain with pine results in such mixtures requiring compaction such as briquetting.

\subsection{Characterization of the briquettes}

The briquettes produced from coffee residues and pinewood in ratios of $25 \%, 50 \%, 75 \%$ as well as the briquettes from each individual biomass sample showed satisfactory visual appearance: good uniformity, absence of cracks, with smooth and shiny surfaces. The produced briquettes are presented in Fig. 2.

Figure 2. Briquettes produced from coffee residues mixed with pinewood in different ratios.

One way of evaluating the briquetting process is by measuring the compaction rate, which represents the ratio between the apparent density of the briquette (Fig. 3B) and the bulk density of the feedstock. Higher compaction rates indicate a higher reduction of the briquette's volume during the densification process, which likely results in a density gain. Table 3 shows the average values obtained for the compaction rate in relation to the proportion of pine.

310 Table 3. Compaction rate of the briquettes produced with studied biomasses. 
It was observed that the pinewood briquettes have a compaction rate nearly three times higher than the ones produced from the residues without pine addition. This is due to the significant difference between the bulk densities of the materials: lower bulk density increases the likelihood of compressing the material. As a result, the compaction rate of the mixtures with $75 \%$ of pinewood and $25 \%$ of coffee residues showed the highest values in volume reduction. The residues with higher initial density would require higher energy to produce the briquette since these materials present greater resistance to densification. In this sense, the addition of pinewood in briquettes, mostly at 50\% and $75 \%$ can contribute to increasing the density without the need of spending additional energy to increase the pressure in the compaction stage.

\subsubsection{Physical - chemical characterization}

The average values of equilibrium moisture content, compressive strength, apparent density and energy density of briquettes are illustrated in Fig. 3.

Figure 3. Properties of briquettes produced with the studied biomasses: equilibrium moisture content (upper-left), apparent density (upper-right), energy density (lower-left), and compressive strength (lower-right).

Equilibrium moisture content is a notably important parameter for evaluating the possible changes in physical conditions of biomass briquettes during storage and transportation. The briquettes with low equilibrium moisture content (5-12 wt $\%$ ) are better suited for transportation not only with respect to the lower concentrations of water carried in the biomass material but also due to increased physical and mechanical resistances of such low-moisture briquettes [46], [65]. Additionally, a higher EMC level complicates the ignition of the fuel and leads to lower energy density values due to the inverse relationship between the EMC and the net heating value [46]. The equilibrium moisture content for the majority of the produced briquettes was observed to be in a relatively narrow range between 9 and 10.3 wt $\%$ with little effect from the pine addition (Fig. 3A). Consequently, these briquettes can be handled more efficiently during storage and transportation. As for the parchment, the increase of pine proportion decreased the briquettes EMC: from $11.9 \mathrm{wt} \%$ in the case of purely parchment briquettes to $10.3 \mathrm{wt} \%$ in the case of $75 \%$ of pine in the blend.

The measurement of apparent density after densification is essential for the evaluation of the biomass potential: lower density raises the costs of transportation and decreases the energy 
density. The apparent density of the briquettes increases with the share of pine in the mixture for stem, primary branch, secondary branch and wood mix (Fig. 3b) from $996.7 \mathrm{~kg} \cdot \mathrm{m}^{-3}-1054 \mathrm{~kg} \cdot \mathrm{m}^{-}$ ${ }^{3}$ to $1136.1 \mathrm{~kg} \cdot \mathrm{m}^{-3}$ which represents a nearly $10 \%$ increase in density. This is due to higher compaction rate of the briquettes with greater percentage of fines. In case of the briquettes with parchment in their composition, the addition of pine only slightly decreases the apparent density of the samples, likely due to the high basic density of the parchment. The values observed in this work are similar to briquettes produced with eucalypt sawdust $\left(1060 \mathrm{~kg} \cdot \mathrm{m}^{-3}\right)$, corn residues $\left(1159 \mathrm{~kg} \cdot \mathrm{m}^{-3}\right)$ and coffee husk $\left(1248 \mathrm{~kg} \cdot \mathrm{m}^{-3}\right)$ [38].

The energy density indicates the energy content per volume unit and affects the efficiency of subsequent use of the briquettes [66]. The energy density of all produced briquettes increased with the addition of pinewood to the coffee residuals due to the higher heating value of the pine (Fig. 3c). The energy density of briquettes with parchment in their composition presented the highest average values for high bulk density, with increments of up to $700 \mathrm{MJ} \cdot \mathrm{m}^{-3}$ corresponding to every $25 \%$ addition of pinewood. However, the residue that showed the greatest variation in this property was that of primary branches with an increase of $3551 \mathrm{MJ} \cdot \mathrm{m}^{-3}$ from the absence of pine to $75 \%$ of pine in the mixture; the increments were of approximately $1184 \mathrm{MJ} \cdot \mathrm{m}^{-3}$ for every $25 \%$ of pinewood addition.

The tensile strength of diametric compression and maximum force is related to the ability of briquettes to withstand mechanical impacts during storage and transport. The briquettes with low resistance tend to disintegrate more quickly, which can cause problems during their combustion. [42] concluded that the size of particles, chemical composition, lignin content, compaction rate and equilibrium moisture content influence the tensile strength of the briquettes. In this study, it was observed that the resistance to diametric compression and maximum force increased in conjunction with the increase of the pine briquette content for all studied materials (Fig. 3D). The highest values were found for the briquettes produced from pine alone. This result is probably due to the low volumetric expansion after the densification of the mixtures because of the presence of fines, low EMC and high lignin content of the pine.

\subsection{Identity model test for the physical-chemical properties measured in the briquettes}

The obtained results confirm the similarity of the biomasses' behavior in the majority of the cases and likely explain the dependencies of the studied properties with the general equations. 
However, this is only possible for the maximum resistance property due to the covariance analysis (Table 4), which reveals a higher p-value than the level of significance $\alpha=0.05$, contrary to EMC, energy density and apparent density properties.

Table 4. Covariance analysis for the properties measured in the briquettes.

As a result, the data were regrouped without the presence of the coffee berry parchment for the energy density and apparent density properties. The analysis of covariance showed that the equations present similar estimates in relation to the behavior of the briquettes with the pinewood addition. Model identity tests for the equilibrium moisture property indicated that it is not advisable to apply a single equation adjusted for the data set. Meanwhile, for stem - wood and primary branch - secondary branch mixtures, a single adjusted equation can be used to represent the data set of these biomasses.

Table 5 shows the parameters of the models for the measured properties as a function of the proportion of pine wood (Eq. 2), according to the adjustments made by the model identity test. These results have a significant importance, once the adjusted models could be used to estimate the value of the physical-chemical properties of briquettes by varying the proportion of pinewood in the mixture.

Table 5. Adjusted equation for the physical - chemical properties of briquettes.

\section{CONCLUSION}

In this study, it was demonstrated that the residues from the coffee production chain such as stems, primary branches and secondary branches of coffee shrubs and the parchment of coffee berries can be used to produce briquettes for combustion processes when mixed with pine wood, creating a new source for the utilization of undervalued residual biomasses. The mechanical strength obtained from coffee residues alone was quite low. However, when blended with pine wood, strong and high-quality briquettes can be produced. The resulting briquettes present a regular format and homogeneous constitution, characteristics that are indicative of better quality and durable products after handling, transportation and storage. additionally, the high energy density of the briquettes produced presents an attractive advantage for increasing the Brazilian energy production matrix using densified material. 


\section{ACKNOWLEDGMENTS}

This work was kindly supported by the Conselho Nacional de Desenvolvimento Científico e Tecnológico (CNPq), Brazil. The authors also thank other contributing research institutions including the Federal University of Minas Gerais - Brazil, the Federal University of Viçosa Brazil, and Lappeenranta University of Technology - Finland.

\section{REFERENCES}

[1] V. Ferreira-Leitao, L. M. F. Gottschalk, M. A. Ferrara, A. L. Nepomuceno, H. B. C. Molinari, and E. P. S. Bon, Biomass residues in Brazil: Availability and potential uses, Waste and Biomass Valorization, 1 (2010) 65-76.

[2] L. A. B. Cortez, E. S. Lora, E. O. Gomez, Biomassa para energia, Unicamp, Brazil, 1st Ed. 2008.

[3] F. Santos, J. L. Colodette, and J. H. de Queiroz, Bioenergia \& Biorrefinaria Cana de Açucar \& Espécies Florestais, UFV, Brazil, 1st Ed. 2013.

[4] J. O. dos Santos, R. M. de Sousa Santos, L. M. da Costa, A. C. de Medeiros, D. C. Coelho, and P. B. Maracajá, Production and use of briquettes in Brazil, Rev. Bras. Agrotecnologia. 5 (1) (2015) 36-40.

[5] F. F. Felfli, J. M. Mesa P, J. D. Rocha, D. Filippetto, C. A. Luengo, and W. A. Pippo, Biomass briquetting and its perspectives in Brazil, Biomass and Bioenergy. 35 (1) (2011) $236-242$.

[6] J. Karlhager, The Swedish Market for Wood Briquettes: Production and Market Development, Master Thesis, Swedish University of Agricultural Sciences, Sweden. 2008.

[7] M. Temmerman, F. Rabier, P. D. Jensen, H. Hartmann, and T. Böhm, Comparative study of durability test methods for pellets and briquettes, Biomass and Bioenergy. 30 (11) (2006) 964-972.

[8] A. Gendek, M. Aniszewska, J. Malaták, and J. Velebil, Evaluation of selected physical and mechanical properties of briquettes produced from cones of three coniferous tree species, Biomass and Bioenergy. 117 (2018) 173-179. 
[9] C. S. Chou, S. H. Lin, and W. C. Lu, Preparation and characterization of solid biomass fuel made from rice straw and rice bran, Fuel Process. Technol. 90 (7-8) (2009) 980-987.

[10] A. Yank, M. Ngadi, and R. Kok, Physical properties of rice husk and bran briquettes under low pressure densification for rural applications, Biomass and Bioenergy. 84 (2016) 22-30.

[11] C. S. Chou, S. H. Lin, C. C. Peng, and W. C. Lu, The optimum conditions for preparing solid fuel briquette of rice straw by a piston-mold process using the Taguchi method, Fuel Process. Technol. 90 (7-8) 2009 1041-1046.

[12] M. Lubwama and V. A. Yiga, Characteristics of briquettes developed from rice and coffee husks for domestic cooking applications in Uganda, Renew. Energy. 118 (2018) 43-55.

[13] A. Amaya, N. Medero, N. Tancredi, H. Silva, and C. Deiana, Activated carbon briquettes from biomass materials, Bioresour. Technol. 98 (8) (2007) 1635-1641.

[14] R. I. Muazu and J. A. Stegemann, Effects of operating variables on durability of fuel briquettes from rice husks and corn cobs, Fuel Process. Technol. 133 (2015) 137-145.

[15] J. Oladeji, Fuel characterization of briquettes produced from corncob and rice husk resides, Pacific J. Sci. Technol. 11 (1) (2010) 101-106.

[16] A. A. Salema, M. T. Afzal, and L. Bennamoun, Pyrolysis of corn stalk biomass briquettes in a scaled-up microwave technology, Bioresour. Technol. 233 (2017) 353-362.

[17] N. Kaliyan and R. V. Morey, Natural binders and solid bridge type binding mechanisms in briquettes and pellets made from corn stover and switchgrass, Bioresour. Technol. 101 (3) (2010) 1082-1090.

[18] M. Brožek, A. Nováková, and M. Kolářová, Quality evaluation of briquettes made from wood waste, Res. Agric. Eng. 58 (1) (2012) 30-35.

[19] M. C. Echeverria and M. Nuti, Valorisation of the Residues of Coffee Agro-industry: Perspectives and Limitations, Open Waste Manag. J. 10 (1) (2017) 13-22.

[20] Brazilian Institute of Geography and Statistics, Agriculture and Livestock Census 2017. (2018). [Online]. Available: https://sidra.ibge.gov.br/home/lspa/brasil. [Accessed: 25-Apr- 
2018].

[21] J. Dias, D. R.; Valencia, N. R.; Franco, D. A. Z.; Lopéz-Núñes, Management and utilization of wastes from coffee processing, Cocoa coffee Ferment., no. Boca Raton: CRC Taylor \& Francis. (2014) 376-382.

[22] P. S. Murthy and M. Madhava Naidu, Sustainable management of coffee industry byproducts and value addition - A review, Resour. Conserv. Recycl. 66 (2012) 45-58.

[23] F. Passos, P. H. M. Cordeiro, B. E. L. Baeta, S. F. de Aquino, and S. I. Perez-Elvira, Anaerobic co-digestion of coffee husks and microalgal biomass after thermal hydrolysis, Bioresour. Technol. 253 (2018) 49-54.

[24] L. Wilson, G. R. John, C. F. Mhilu, W. Yang, and W. Blasiak, Coffee husks gasification using high temperature air/steam agent, Fuel Process. Technol., 91 (10) (2010) 13301337.

[25] T. M. Ismail, M. Abd El-Salam, E. Monteiro, and A. Rouboa, Eulerian - Eulerian CFD model on fluidized bed gasifier using coffee husks as fuel, Appl. Therm. Eng. 106 (2016) 1391-1402.

[26] J. L. De Oliveira, J. N. Da Silva, E. Graciosa Pereira, D. Oliveira Filho, and D. Rizzo Carvalho, Characterization and mapping of waste from coffee and eucalyptus production in Brazil for thermochemical conversion of energy via gasification, Renew. Sustain. Energy Rev. 21 (2013) 52-58.

[27] C. A. García, Á. Peña, R. Betancourt, and C. A. Cardona, Energetic and environmental assessment of thermochemical and biochemical ways for producing energy from agricultural solid residues: Coffee Cut-Stems case, J. Environ. Manage. 216 (2017) 160168.

[28] C. M. S. da Silva et al., Biomass torrefaction for energy purposes - Definitions and an overview of challenges and opportunities in Brazil, Renew. Sustain. Energy Rev. 82 (2018) 2426-2432.

[29] J. O. Brito, F. G. Silva, M. M. Leão, and G. Almeida, Chemical composition changes in eucalyptus and pinus woods submitted to heat treatment, Bioresour. Technol. 99 (18) 
(2008) 8545-8548.

486

[30] C. L. Mendoza Martinez et al., Characterization of residual biomasses from the coffee production chain and assessment the potential for energy purposes, Biomass and Bioenergy, 120 (2019) 68-76.

[31] DIN, German Institute for Standardizatios: DIN EN ISO 14780:2017 Solid biofuels Sample preparation. 2017.

[32] DIN, German Institute for Standardization: DIN EN 14774-1 Solid biofuels Determination of moisture content, 2010.

[33] DIN, German Institute for Standardization: DIN EN 14775 - Solid biofuels Determination of ash content. 2012.

[34] DIN, German Institute for Standardization: DIN EN 15148 - Solid biofuels Determination of the content of volatile matter, 2010.

[35] DIN, German Institute for Standardization: DIN EN 15103 - Solid biofuels Determination of bulk density, 2010.

[36] DIN, German Institute for Standardization: DIN EN 14918 - Solid biofuels Determination of calorific value, 2014.

[37] B. R. Vital, Métodos de determinação da densidade da madeira, Viçosa, MG:SIF, 1984.

[38] T. de P. Protásio, I. C. N. Alves, P. F. Trugilho, V. O. Silva, and A. E. R. Baliza, Compactação de biomassa vegetal visando à produção de biocombustíveis sólidos, Pesqui. Florest. Bras. 31(68) (2011) 273-283.

[39] Soft, S, STATISTICA (data analysis software system), version 8.0, 2007.

[40] A. J. Regazzi and C. H. O. Silva, Testes para verificar a igualdade de parâmetros e a identidade de modelos de regressão não-linear em dados de experimento com delineamento em blocos casualizados, Rev. Ceres. 57 (3) (2010) 315-320.

[41] S. Mani, L. G. Tabil, and S. Sokhansanj, Effects of compressive force, particle size and moisture content on mechanical properties of biomass pellets from grasses, Biomass and Bioenergy. 30 (7) (2006) 648-654. 
[42] N. Kaliyan and R. Vance Morey, Factors affecting strength and durability of densified biomass products, Biomass and Bioenergy. 33 (3) (2009) 337-359.

[43] L. Guo, L. G. Tabil, D. Wang, and G. Wang, Influence of moisture content and hammer mill screen size on the physical quality of barley, oat, canola and wheat straw briquettes, Biomass and Bioenergy. 94 (2016) 201-208.

[44] S. Mani, L. G. Tabil, and S. Sokhansanj, Grinding performance and physical properties of wheat and barley straws, corn stover and switchgrass, Biomass and Bioenergy. 27 (4) (2004) 339-352.

[45] S. J. Mitchual, K. Frimpong-Mensah, and N. A. Darkwa, Effect of species, particle size and compacting pressure on relaxed density and compressive strength of fuel briquettes, Int. J. Energy Environ. Eng. 4 (1) (2013) 1-6.

[46] J. S. Tumuluru, C. T. Wright, J. R. Hess, and K. L. Kenney, A review of biomass densification systems to develop uniform feedstock commodities for bioenergy application, Biofuels, Bioproducts and Biorefining. 5 (6) (2011) 683-707.

[47] S. Mani, L. G. Tabil, and S. Sokhansanj, Specific energy requirement for compacting corn stover, Bioresour. Technol. 97 (12) (2006) 1420-1426.

[48] W. Quirino, Utilização energética de resíduos vegetais. 2002.

[49] P. D. Grover and S. K. Mishra, Biomass Briquetting: Technology and Practices, Reg. Wood Energy Dev. Program. Asia, (46) (1996) 1-48.

[50] Y. Li and H. Liu, High-pressure densification of wood residues to form an upgraded fuel, Biomass and Bioenergy, 19 (3) (2000) 177-186.

[51] I. Obernberger and G. Thek, Physical characterisation and chemical composition of densified biomass fuels with regard to their combustion behaviour, Biomass and Bioenergy. 27 (6) (2004) 653-669.

[52] M. Brožek, The Effect of Moisture of the Raw Material on the Properties Briquettes for Energy Use, Acta Univ. Agric. Silvic. Mendelianae Brun. 64 (2016) 1453-1458.

[53] E. R. K. Fernandes, C. Marangoni, O. Souza, and N. Sellin, Thermochemical 
characterization of banana leaves as a potential energy source, Energy Convers. Manag., 75 (2013) 603-608.

[54] R. García, C. Pizarro, A. Lavín, J. Bueno. Characterization of Spanish biomass wastes for energy use, Bioresource Technology. 103 (1) (2012) 249-258.

[55] B. M. Jenkins, Fuel properties for biomass materials, International symposium on Application and Management of Energy in Agriculture: The Role of Biomass Fuels. New Delhi, 1990.

[56] S. Munir, S. S. Daood, W. Nimmo, A. M. Cunliffe, and B. M. Gibbs, Thermal analysis and devolatilization kinetics of cotton stalk, sugar cane bagasse and shea meal under nitrogen and air atmospheres, Bioresour. Technol. 100 (3) (2009) 1413-1418.

[57] L. Yanfen and M. Xiaoqian, Thermogravimetric analysis of the co-combustion of coal and paper mill sludge, Appl. Energy. 87 (11) (2010) 3526-3532.

[58] Nogueira, L. A. H., Lora, E. E. S., Trossero, M. A., Frisk, T., Dendroenergia: fundamentos e aplicações. National Electric Power Agency of Brazil, 2000.

[59] T. Raj et al., Physical and chemical characterization of various indian agriculture residues for biofuels production,Energy and Fuels. 29 (5) (2015) 3111-3118.

[60] I. Obernberger and G. Thek, The pellet handbook: The production and thermal utilisation of biomass pellets. 2010.

[61] J. Diniz, A. D. L. Cardoso, J. A. Stahl, M. A. Villetti, and A. F. Martins, Poder Calorífico da Casca de Arroz, Caroço de Pêssego, Serragem de Eucalipto e de seus Produtos de Pirólise, Ciência e Natura. 26 (2) (2004) 25-32.

[62] S. Nanda, P. Mohanty, K. K. Pant, S. Naik, J. A. Kozinski, and A. K. Dalai, Characterization of North American Lignocellulosic Biomass and Biochars in Terms of their Candidacy for Alternate Renewable Fuels, Bioenergy Res. 6 (2) (2013) 663-677.

[63] V. C. Soares, M. L. Bianchi, P. F. Trugilh, J. Höfler, and A. J. Pereira, Análise das propriedades da madeira e do carvão vegetal de híbridos de eucalipto em três idades, Cerne. 21 (2) (2015) 191-197. 
2

3

4566

6567

8

9568 10

[64] A. Demirbaş, Biomass resource facilities and biomass conversion processing for fuels and chemicals, Energy Convers. Manag. 42 (11) (2001) 1357-1378.

[65] N. V. Avelar, A. A. P. Rezende, A. de C. O. Carneiro, and C. M. Silva, Evaluation of briquettes made from textile industry solid waste, Renew. Energy. 91 (2016) 417-424.

[66] Rodrigues, V. A. J., Silva, C. M., Carneiro, A. C. O., Rezende, A. A. P., Santos, L. S., \& Ikawa, G. A., The use of pulp mill solid wastes for energy production. Proceedings of the 3th International Symposium on Energy from Biomass and Waste. (2010) 8-11. 
61

62

63
Table 1. Particle size distribution of the lignocellulosic residues used in the production of briquettes.

\begin{tabular}{ccc|c|c}
\hline \multirow{2}{*}{ Biomass material } & \multirow{2}{*}{ Designation } & \multicolumn{3}{c}{ Particle size $[\mathrm{mm}]$} \\
\cline { 4 - 5 } & & $\emptyset<0.31$ & $0.31 \leq \emptyset<0.47$ & $0.47 \leq \emptyset \leq 2$ \\
\hline Pine & Wood & $60.3 \%$ & $19.0 \%$ & $20.7 \%$ \\
\multirow{2}{*}{ Coffee } & Stem & $51.2 \%$ & $22.2 \%$ & $26.6 \%$ \\
& Primary Branch & $47.5 \%$ & $21.4 \%$ & $31.1 \%$ \\
& Secondary Branch & $45.1 \%$ & $16.6 \%$ & $38.3 \%$ \\
& Parchment & $21.9 \%$ & $35.3 \%$ & $42.8 \%$ \\
\hline
\end{tabular}


Table 2. Chemical characterization of the lignocellulosic residues.

\begin{tabular}{cccccccc}
\hline \multirow{2}{*}{ Parameter } & \multirow{2}{*}{ Unit } & \multicolumn{7}{c}{ Biomasses } \\
\cline { 3 - 8 } & & PW & CS & PB & SB & MIX & CCP \\
\hline MC & wt \% & $12.23 \mathrm{a}$ & $10.96 \mathrm{a}$ & $8.70 \mathrm{c}$ & $9.28 \mathrm{~b}$ & $9.65 \mathrm{~b}$ & $11.09 \mathrm{a}$ \\
$\mathrm{VM}^{\mathrm{a}}$ & wt $\%$ & $82.46 \mathrm{a}$ & $79.76 \mathrm{ab}$ & $80.67 \mathrm{a}$ & $76.50 \mathrm{bc}$ & $79.57 \mathrm{ab}$ & $73.80 \mathrm{c}$ \\
FC $^{\mathrm{a}}$ & wt $\%$ & $16.79 \mathrm{~b}$ & $18.09 \mathrm{ab}$ & $17.05 \mathrm{ab}$ & $19.36 \mathrm{ab}$ & $14.62 \mathrm{~d}$ & $20.09 \mathrm{ab}$ \\
$\mathrm{AC}^{\mathrm{a}}$ & wt $\%$ & $0.75 \mathrm{~d}$ & $2.15 \mathrm{c}$ & $2.27 \mathrm{c}$ & $4.14 \mathrm{~b}$ & $2.63 \mathrm{c}$ & $5.91 \mathrm{a}$ \\
$\mathrm{HHV}$ & $\mathrm{MJ} / \mathrm{kg}$ & $20.71 \mathrm{a}$ & $20.12 \mathrm{~b}$ & $19.75 \mathrm{bc}$ & $19.72 \mathrm{c}$ & $19.86 \mathrm{bc}$ & $18.92 \mathrm{~d}$ \\
\hline
\end{tabular}

adry basis; MC-moisture content; VM-volatile matter; FC-fixed carbon content; AC-ash content; HHV-higher heating value; PW-pinewood; CS-coffee stem; PB-primary branch; SB-secondary branch; MIX=CS+PB+SB; CCPCoffee Cherry Parchment.

614 Averages along the rows followed by the same letter among biomasses do not differ by Tukey test at 5\% of significance. 
2

629

6

7630

8

631

632

13

14

15

16

17

18

19

20

21

22633

23634

24

25635

26

27

28636

29

$\begin{array}{ll}30 & 637\end{array}$

31

32

33

34

$\begin{array}{ll}35 & 639\end{array}$

36

37

$38 \quad 640$

39

40641

41

42

43642

44

45

46

47

$48 \quad 644$

49

$\begin{array}{ll}50 & 645\end{array}$

51

52

53646

54

$\begin{array}{ll}55 & 647\end{array}$

57

$\begin{array}{lll}58 & 648\end{array}$

59

60

61

62

63

64

65

Table 3. Compaction rate of the briquettes produced with studied biomasses.

\begin{tabular}{c|ccccc}
\hline \multirow{2}{*}{ PW $(\%)$} & \multicolumn{5}{|c}{ Biomasses } \\
\cline { 2 - 6 } & CS & PB & SB & MIX & CCP \\
\hline 0 & 3.67 & 3.92 & 4.43 & 4.53 & 3.48 \\
25 & 5.02 & 15.16 & 16.25 & 17.23 & 14.58 \\
50 & 18.81 & 21.64 & 19.30 & 19.52 & 20.13 \\
75 & 24.12 & 24.29 & 25.86 & 25.41 & 25.88 \\
100 & 11.78 & 11.78 & 11.78 & 11.78 & 11.78
\end{tabular}

PW-pinewood; CS-coffee stem; PB-primary branch; SB-secondary branch; MIX=CS+PB+SB; CCP-Coffee Cherry Parchment 
Table 4. Covariance analysis for the properties measured in the briquettes.

\begin{tabular}{|c|c|c|c|c|c|}
\hline VS & $\mathrm{DF}$ & SQ & MQ & $\mathrm{F}$ & $\mathrm{P}(>\mathrm{F})$ \\
\hline \multicolumn{6}{|c|}{ Equilibrium moisture content } \\
\hline IM & 4 & 4 & 1 & 8.15 & $0.62 \mathrm{E}-04$ \\
\hline Residual & 18 & 2.21 & 0.12 & & \\
\hline \multicolumn{6}{|c|}{ Energy density } \\
\hline IM & 4 & 1771328 & 442832 & 3.04 & 0.043 \\
\hline Residual & 18 & 259174 & 143984 & & \\
\hline \multicolumn{6}{|c|}{ Apparent density } \\
\hline IM & 4 & 23151 & 5788 & 6.60 & $1.88 \mathrm{E}-03$ \\
\hline Residual & 18 & 15784 & 877 & & \\
\hline \multicolumn{6}{|c|}{ Maximum load } \\
\hline IM & 4 & 12001 & 3000 & 2.7035 & 0.06 \\
\hline Residual & 18 & 19976 & 1110 & & \\
\hline
\end{tabular}


Table 5. Adjusted equation for the physical - chemical properties of briquettes.

\begin{tabular}{cllccc}
\hline \multirow{2}{*}{ Property } & \multicolumn{1}{c}{ Treatment } & \multicolumn{2}{c}{ Adjusted Equation } & \multirow{2}{*}{$\mathbf{R}^{\mathbf{2}}$} \\
\cline { 3 - 6 } & & $\boldsymbol{\beta}_{\mathbf{0}}$ & $\boldsymbol{\beta}_{\mathbf{1}}$ & $\boldsymbol{\beta}_{\mathbf{2}}$ & \\
\hline \multirow{3}{*}{ Equilibrium moisture } & CS-MIX model & $2 \mathrm{E}-06$ & $2.1 \mathrm{E}-03$ & 9.65 & 0.99 \\
\cline { 2 - 5 } & PB-SB model & $9 \mathrm{E}-05$ & $-1.3 \mathrm{E}-02$ & 10.23 & 0.76 \\
\cline { 2 - 5 } & CCP model & $3 \mathrm{E}-05$ & $-2.3 \mathrm{E}-02$ & 11.84 & 0.99 \\
\hline \multirow{2}{*}{ Energy density } & General model & $-1.9 \mathrm{E}-01$ & 46.60 & 16835 & 0.99 \\
\cline { 2 - 5 } & CCP model & $-1.8 \mathrm{E}-01$ & 35.34 & 17995 & 0.93 \\
\hline \multirow{2}{*}{ Apparent density } & General model* & $-4.3 \mathrm{E}-03$ & 1.5 & 1027 & 0.99 \\
\cline { 2 - 5 } & CCP model & $1 \mathrm{E}-05$ & $-4.4 \mathrm{E}-01$ & 1185 & 0.85 \\
\hline Maximum load & General model & $3.2 \mathrm{E}-02$ & 2.5 & 139 & 0.99 \\
\hline
\end{tabular}

*Adjusted equation for briquettes without presence of CCP in its composition; CS - Coffee Stem; PB - Primary Branch; SB - Secondary Branch; Mix=CS+PB+SB; CCP - Coffee Cherry Parchment. $\mathrm{R}^{2}$ - Coefficient of determination. $\beta_{0}, \beta_{1}, \beta_{2}$ - Regression coefficients. 4 


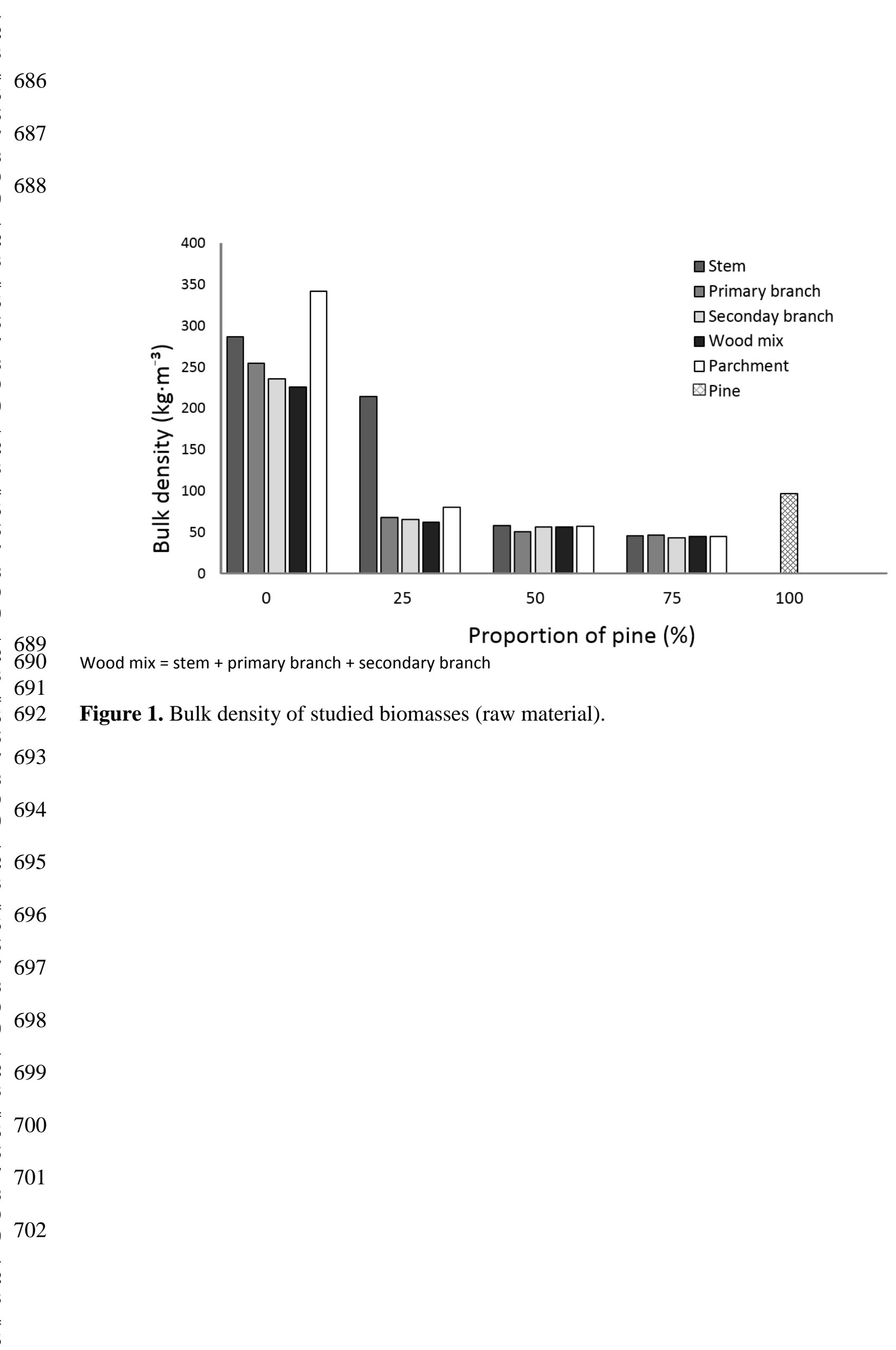



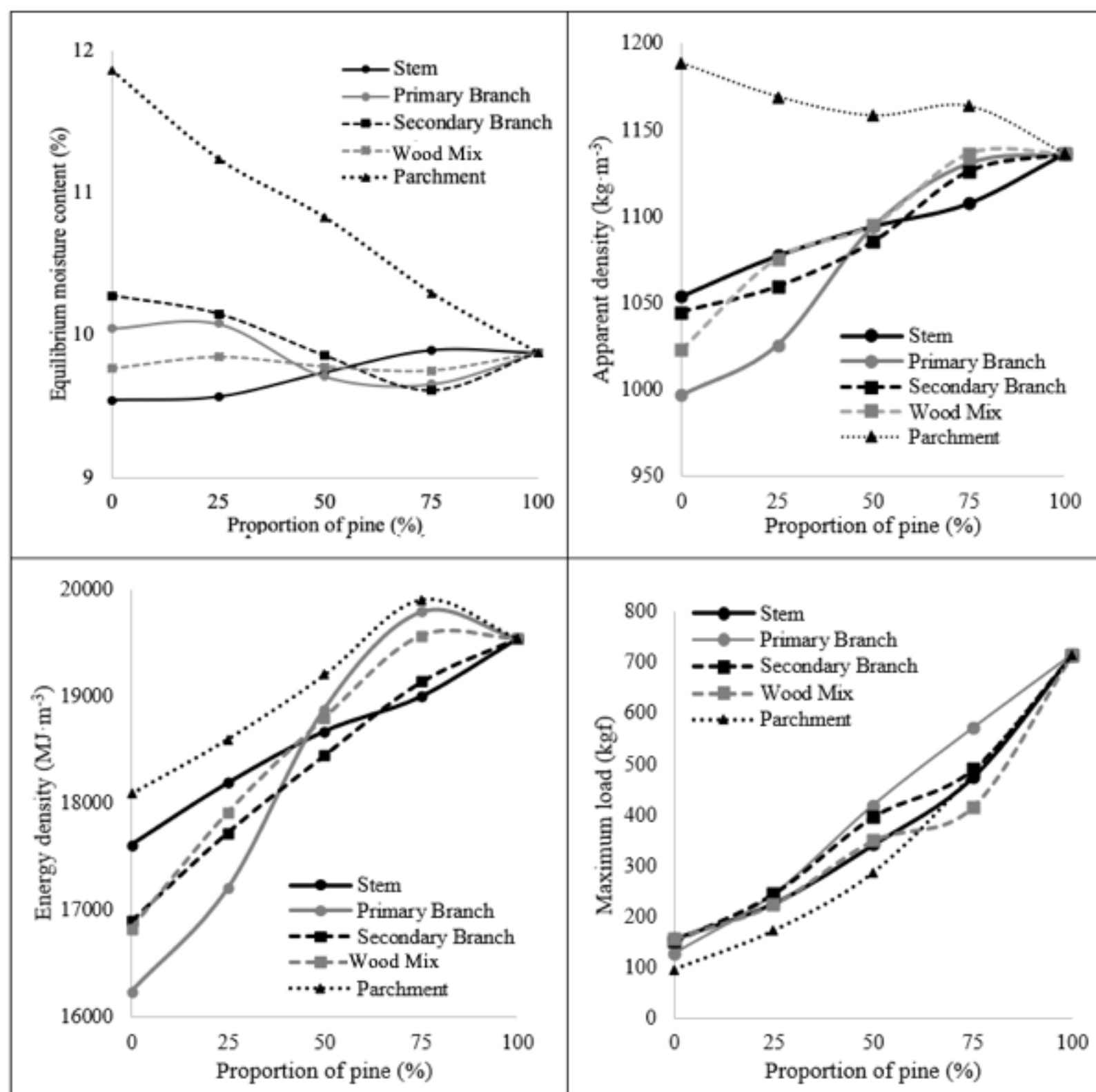

Figure 3. Properties of briquettes produced with the studied biomasses: equilibrium moisture content (upper-left), apparent density (upper-right), energy density (lower-left) and compressive 
Table 1. Particle size distribution of the lignocellulosic residues used in the production of briquettes.

\begin{tabular}{ccc|c|c}
\hline \multirow{2}{*}{ Biomass material } & \multirow{2}{*}{ Designation } & \multicolumn{3}{c}{ Particle size [mm] } \\
\cline { 4 - 5 } & & $\emptyset<0.31$ & $0.31 \leq \emptyset<0.47$ & $0.47 \leq \emptyset \leq 2$ \\
\hline Pine & Wood & $60.3 \%$ & $19.0 \%$ & $20.7 \%$ \\
\multirow{2}{*}{ Coffee } & Stem & $51.2 \%$ & $22.2 \%$ & $26.6 \%$ \\
& Primary Branch & $47.5 \%$ & $21.4 \%$ & $31.1 \%$ \\
& Secondary Branch & $45.1 \%$ & $16.6 \%$ & $38.3 \%$ \\
& Parchment & $21.9 \%$ & $35.3 \%$ & $42.8 \%$ \\
\hline
\end{tabular}


Table 2. Chemical characterization of the lignocellulosic residues.

\begin{tabular}{cccccccc}
\hline \multirow{2}{*}{ Parameter } & \multirow{2}{*}{ Unit } & \multicolumn{7}{c}{ Biomasses } \\
\cline { 3 - 8 } & & PW & CS & PB & SB & MIX & CCP \\
\hline MC & wt \% & $12.23 \mathrm{a}$ & $10.96 \mathrm{a}$ & $8.70 \mathrm{c}$ & $9.28 \mathrm{~b}$ & $9.65 \mathrm{~b}$ & $11.09 \mathrm{a}$ \\
VM $^{\mathrm{a}}$ & wt $\%$ & $82.46 \mathrm{a}$ & $79.76 \mathrm{ab}$ & $80.67 \mathrm{a}$ & $76.50 \mathrm{bc}$ & $79.57 \mathrm{ab}$ & $73.80 \mathrm{c}$ \\
FC $^{\mathrm{a}}$ & wt $\%$ & $16.79 \mathrm{~b}$ & $18.09 \mathrm{ab}$ & $17.05 \mathrm{ab}$ & $19.36 \mathrm{ab}$ & $14.62 \mathrm{~d}$ & $20.09 \mathrm{ab}$ \\
$\mathrm{AC}^{\mathrm{a}}$ & wt $\%$ & $0.75 \mathrm{~d}$ & $2.15 \mathrm{c}$ & $2.27 \mathrm{c}$ & $4.14 \mathrm{~b}$ & $2.63 \mathrm{c}$ & $5.91 \mathrm{a}$ \\
$\mathrm{HHV}$ & $\mathrm{MJ} / \mathrm{kg}$ & $20.71 \mathrm{a}$ & $20.12 \mathrm{~b}$ & $19.75 \mathrm{bc}$ & $19.72 \mathrm{c}$ & $19.86 \mathrm{bc}$ & $18.92 \mathrm{~d}$ \\
\hline
\end{tabular}

adry basis; MC-moisture content; VM-volatile matter; FC-fixed carbon content; AC-ash content; HHV-higher heating value; $\mathrm{PW}$-pinewood; CS-coffee stem; PB-primary branch; SB-secondary branch; MIX=CS+PB+SB; CCP-Coffee Cherry Parchment.

Averages along the rows followed by the same letter among biomasses do not differ by Tukey test at $5 \%$ of significance. 
Table 3. Compaction rate of the briquettes produced with studied biomasses.

\begin{tabular}{c|ccccc}
\hline \multirow{2}{*}{ PW (\%) } & \multicolumn{5}{|c}{ Biomasses } \\
\cline { 2 - 5 } & CS & PB & SB & MIX & CCP \\
\hline 0 & 3.67 & 3.92 & 4.43 & 4.53 & 3.48 \\
25 & 5.02 & 15.16 & 16.25 & 17.23 & 14.58 \\
50 & 18.81 & 21.64 & 19.30 & 19.52 & 20.13 \\
75 & 24.12 & 24.29 & 25.86 & 25.41 & 25.88 \\
100 & 11.78 & 11.78 & 11.78 & 11.78 & 11.78 \\
\hline
\end{tabular}

PW-pinewood; CS-coffee stem; PB-primary branch; SB-secondary branch; MIX=CS+PB+SB; CCP-Coffee Cherry Parchment 
Table 4. Covariance analysis for the properties measured in the briquettes.

\begin{tabular}{|c|c|c|c|c|c|}
\hline VS & $\mathrm{DF}$ & SQ & MQ & $\mathrm{F}$ & $\mathrm{P}(>\mathrm{F})$ \\
\hline \multicolumn{6}{|c|}{ Equilibrium moisture content } \\
\hline $\mathrm{IM}$ & 4 & 4 & 1 & 8.15 & $0.62 \mathrm{E}-04$ \\
\hline Residual & 18 & 2.21 & 0.12 & & \\
\hline \multicolumn{6}{|c|}{ Energy density } \\
\hline IM & 4 & 1771328 & 442832 & 3.04 & 0.043 \\
\hline Residual & 18 & 259174 & 143984 & & \\
\hline \multicolumn{6}{|c|}{ Apparent density } \\
\hline IM & 4 & 23151 & 5788 & 6.60 & $1.88 \mathrm{E}-03$ \\
\hline Residual & 18 & 15784 & 877 & & \\
\hline \multicolumn{6}{|c|}{ Maximum load } \\
\hline IM & 4 & 12001 & 3000 & 2.7035 & 0.06 \\
\hline Residual & 18 & 19976 & 1110 & & \\
\hline
\end{tabular}

VS-Variation sources; DF-Degrees of freedom; SQ-Sum square; MQ-Mean square; F-F calculated statistics; p-statistical probability F tabulated; IM-Identity model. 
Table 5. Adjusted equation for the physical - chemical properties of briquettes.

\begin{tabular}{clcccc}
\hline \multirow{2}{*}{ Property } & \multicolumn{1}{c}{ Treatment } & \multicolumn{3}{c}{ Adjusted Equation } & \multirow{2}{*}{$\mathbf{R}^{\mathbf{2}}$} \\
\cline { 2 - 5 } & & $\boldsymbol{\beta}_{\mathbf{0}}$ & $\boldsymbol{\beta}_{\mathbf{1}}$ & $\boldsymbol{\beta}_{\mathbf{2}}$ & \\
\hline \multirow{3}{*}{ Equilibrium moisture } & CS-MIX model & $2 \mathrm{E}-06$ & $2.1 \mathrm{E}-03$ & 9.65 & 0.99 \\
\cline { 2 - 6 } & PB-SB model & $9 \mathrm{E}-05$ & $-1.3 \mathrm{E}-02$ & 10.23 & 0.76 \\
\cline { 2 - 6 } & CCP model & $3 \mathrm{E}-05$ & $-2.3 \mathrm{E}-02$ & 11.84 & 0.99 \\
\hline \multirow{2}{*}{ Energy density } & General model* & $-1.9 \mathrm{E}-01$ & 46.60 & 16835 & 0.99 \\
\cline { 2 - 6 } & CCP model & $-1.8 \mathrm{E}-01$ & 35.34 & 17995 & 0.93 \\
\hline \multirow{2}{*}{ Apparent density } & General model* & $-4.3 \mathrm{E}-03$ & 1.5 & 1027 & 0.99 \\
\cline { 2 - 5 } & CCP model & $1 \mathrm{E}-05$ & $-4.4 \mathrm{E}-01$ & 1185 & 0.85 \\
\hline Maximum load & General model & $3.2 \mathrm{E}-02$ & 2.5 & 139 & 0.99
\end{tabular}

*Adjusted equation for briquettes without presence of CCP in its composition; CS - Coffee Stem; PB Primary Branch; SB - Secondary Branch; Mix=CS+PB+SB; CCP - Coffee Cherry Parchment. $\mathrm{R}^{2}$ Coefficient of determination. $\beta_{0}, \beta_{1}, \beta_{2}-$ Regression coefficients. 


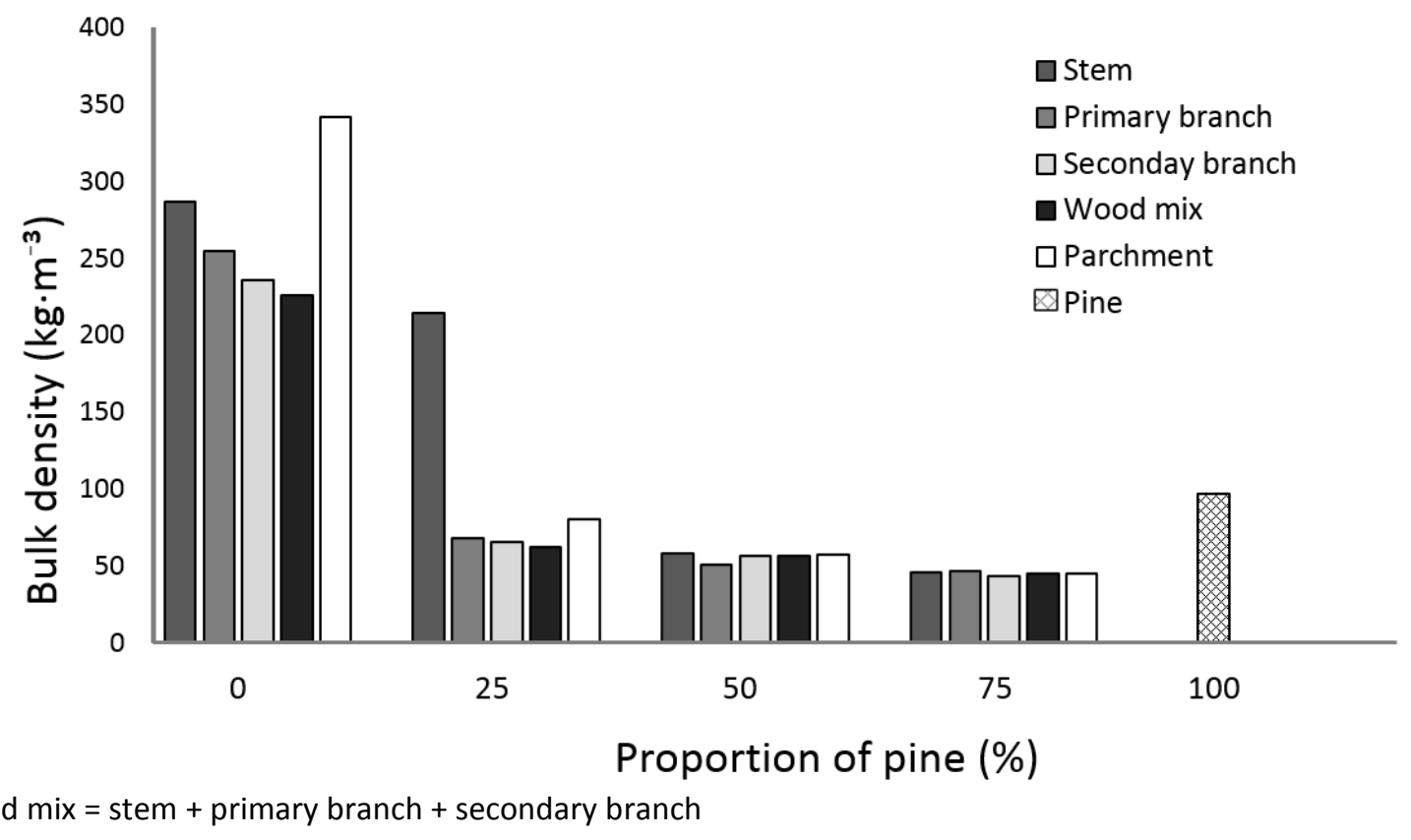

Figure 1. Bulk density of studied biomasses (raw material).

Wood mix = stem + primary branch + secondary branch

rece 


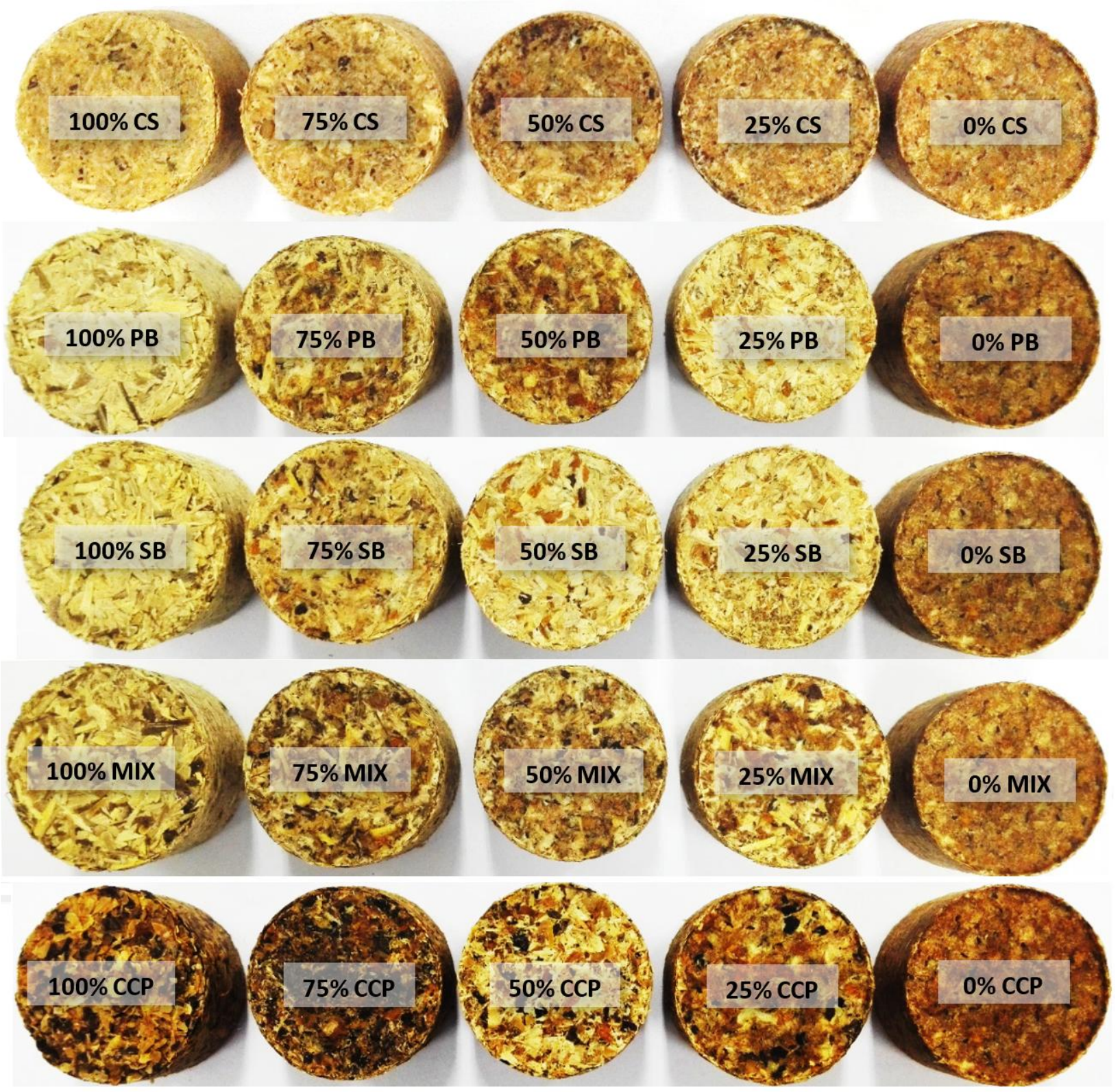

CS-coffee stem; PB-primary branch; SB-secondary branch; MIX=CS+PB+SB; CCP-Coffee Cherry Parchment.

Figure 2. Briquettes produced from coffee residues mixed with pinewood in different ratios. 


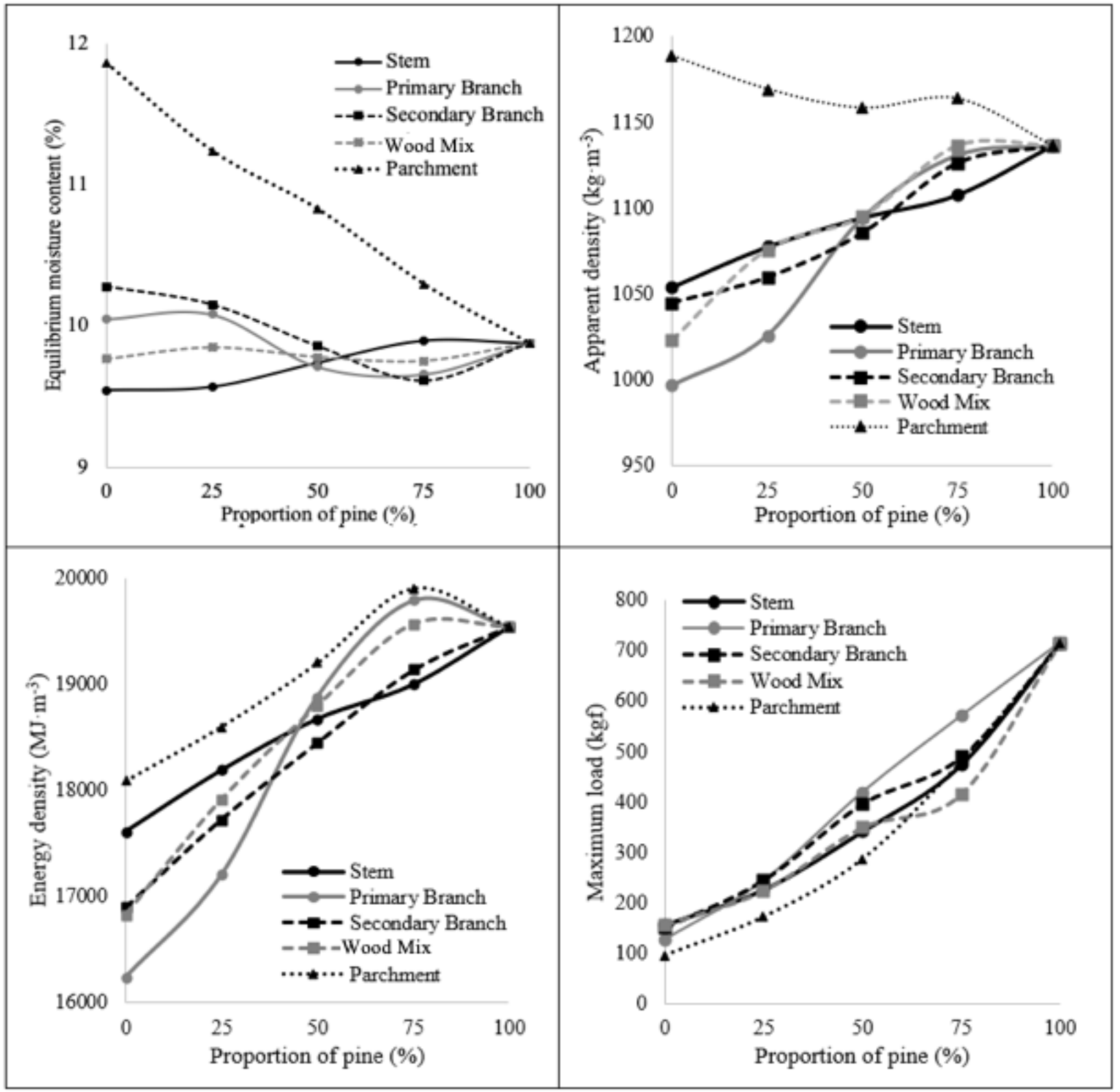

Figure 3. Properties of briquettes produced with the studied biomasses: equilibrium moisture content (upper-left), apparent density (upper-right), energy density (lower-left) and compressive strength (lower-right). 